\title{
Simpósio dos A.B.o. no Congresso Brasileiro: um claro endosso à política editorial vigente
}

\author{
Harley E. A. Bicas \\ Mauro Goldchmit \\ Paulo Elias C. Dantas \\ Vital Paulino Costa
}

Os Arquivos Brasileiros de Oftalmologia pertencem ao Conselho Brasileiro de Oftalmologia. O Conselho Brasileiro de Oftalmologia é dos oftalmologistas brasileiros. Logo, são estes não apenas os destinatários da revista, mas os efetivos diretores de seus caminhos, os que determinam como convém que ela seja. Cabem aos editores as responsabilidades de orientação sobre as vantagens e desvantagens de cada proposta e, uma vez decidida a implantação de uma idéia, concretizá-la.

Se não com estas palavras, foi esse o princípio exposto para objetivar as discussões e deliberações do Simpósio sobre "Propostas de administração e promoção dos Arquivos Brasileiros de Oftalmologia" no XVI Congresso Brasileiro de Prevenção da Cegueira e Reabilitação Visual, realizado no Rio de Janeiro. Uma prova de confiança na tomada de consciência participativa para a gestão da revista e na capacidade de discernimento dos então presentes para promovê-la. De fato, uma revista científica pode aparecer publicada em diferentes modos e com finalidades, se não antagônicas, pelo menos divergentes. Por exemplo: mesmo que ela se atenha a uma linha puramente acadêmica, são possíveis as ofertas de uma face "pedagógica", mais voltada à divulgação e à consolidação de conhecimentos já adquiridos, ou a de uma "científica", referida à pesquisa, à procura do novo e da ultrapassagem das fronteiras do que já se sabe.

Questões desse teor seriam atribuíveis ao Conselho Administrativo da revista, órgão previsto no item " $\mathrm{e}$ " do Instrumento Particular de doação dos "Arquivos Brasileiros de Oftalmologia” e respectiva marca, que faz a família Belfort Mattos ao Conselho Brasileiro de Oftalmologia (dado aos oito dias do mês de setembro do ano dois mil, em Natal, e com registro 2643658 do $1^{\circ}$ Cartório de Títulos e Documentos e Civil de Pessoas Jurídicas de São Paulo, em 29 do mesmo mês) de onde fluiriam as políticas editoriais e as linhas de orientação executiva do Editor-Chefe, a tal colégio subordinado, cujos membros, aliás, já se acham até nomeados, mas sem a legitimação formal da aprovação do respectivo Regimento da revista pelo Conselho Deliberativo do C.B.O., incorporando tal referência ao seu Estatuto. Assim, com a justificativa ética dessa presente falta de normatização política e de balizamento das linhas editoriais então vigentes e a adotar, foram discutidos e votados nessa reunião temas substanciais para a gestão das publicações, colhidos por consulta aos Conselheiros Editoriais, efetivos e "ad hoc".
As cinqüenta e quatro sugestões, idéias ou propostas recebidas foram catalogadas como de Apresentação (da forma como a revista deve se mostrar), de Conteúdos (seção subdividida em Revisões Pedagógicas, Resumos, Notas e Informações, Cartas aos Editores, Outros), Critérios, Métodos (com as subdivisões de Seleção, Avaliação, Agilização, Informatização), Indexação e Outros (com as partes de Decisões, Divulgação, Prêmios e Miscelânea). Para se ter idéia da importância dos debates, as duas primeiras questões foram as de "Publicações de artigos em inglês na íntegra" (entendida como de que toda a revista fosse apresentada em inglês) e "Publicação de artigos apenas em português" (com a exclusão da presente opção de que possam aparecer em inglês ou espanhol). Muito significativos, tanto nesse caso quanto em outros - nos quais se confrontava a possibilidade de adoção de uma nova condição de apresentação e conteúdos da revista contra a de manutenção do modo vigente - foram as decididas conclusões de que os procedimentos atualmente oferecidos deveriam ser continuados. Uma claríssima demonstração de endosso às políticas editoriais imprimidas, trazendo segurança aos editores sobre as conduções das responsabilidades que lhes são atribuídas. E mais ainda, ao se notar que quase todas confirmações foram, quase sempre, consensuais: a de publicação de artigos em português, inglês e espanhol; a de que textos não fossem preliminarmente recusados por suas impropriedades gramaticais (mas com os cuidados de suas correções durante o processo de julgamento, ou depois); a de que a periodicidade se mantivesse (bimestral); a de que não se começasse uma seção nova (como a de "Oftalmologia baseada em evidências", certamente importante, ou a de "Resumos" de artigos relevantes da literatura, mas sem a garantia de que se conservasse sua continuidade, o que redundaria em prejuízos quanto a processos de indexação); a de que não se começasse uma seção de Discussão de Casos Clínicos (com o argumento de que também poderia trazer problemas àqueles objetivos de validação internacional); a de que não se aumentasse ainda mais o rigor e a elitização dos julgamentos (em 2003, de 247 artigos submetidos, apenas 116 foram publicados); a de não privilegiar a publicação de trabalhos pelo fato de serem "mais curtos"; ou a de agilização de análise de tipos de trabalho (por exemplo, os de condensações de Teses em cursos de pós-graduação de sentido estrito) e de outras considerações do gênero.

Por outro lado, como sugestões aprovadas para implanta- 
ção, a de ampliação da seção de Relatos de Casos para inclusão de comunicações curtas; a de inclusão nos questionários de avaliação dos trabalhos da opção "não se aplica" a todos os itens do formulário; a de cartas explicativas a conselheiros que propõem a rejeição de um trabalho (mas que depois o recebem para re-análise, ou o vêem publicado); a de criação de prazos aos autores para devolução de suas correções (trinta dias, podendo esse prazo ser ampliado, a pedido; mas ao contrário, interpretando-se como "auto-rejeição" a falta de devolução ou a da manifestação de interesse nas correções); a de exigibilidade de uso dos processos de informática como qualificação para a consultoria científica da revista (mantendo-se a recepção dos artigos dos autores ou suas respostas na forma tradicional, mas passando suas distribuições e recepção de análises pela rede internacional de informação); a de gestões junto ao C.B.O. para criação do Prêmio Waldemar Belfort Mattos-Rubens Belfort Mattos (em homenagem aos fundadores dos A.B.O.) ao melhor trabalho publicado em cada ano.

Além de concordâncias sobre a conveniência de manutenção de outros critérios e métodos atualmente aplicados; e eventuais esclarecimentos de razões, pelas quais eles prevalecem ou não podem ser mudados (por exemplo, a sugestão de limitação do número de co-autores de um trabalho, obviamente um problema ético dos maiores) surgiram propostas cuja efetivação foge à competência da revista, mas que serão enca- minhadas: a de disponibilidade de listas de oftalmologistas de acordo a seus exercícios de "sub-especialidades", para consultas de tópicos, pela comunidade científica; a de despertar em Residentes a conveniência da leitura dos A.B.O. (ou a de torná-la exigida nos cursos credenciados); a de chamar a atenção de autores para a importância das citações de artigos aqui publicados (base de cálculo para os chamados fatores de impacto, vida média de citações e índice de "imediação"), essenciais às tão sonhadas ampliações de nossas indexações internacionais.

Espera-se que os resultados deste Simpósio sejam motivadores de que em próximos o comparecimento seja ainda mais expressivo em quantidade; já que em qualidade dos debates e aproveitamento de conclusões o nível parece ter sido o maior possível. Nossos agradecimentos aos que tanto para isso colaboraram: a Cláudia Moral (que secretariou a reunião) e A. Duarte, Ana Maria Garcia, Andréa Araújo Zin, Cláudio do Carmo Chaves, Carlos Ramos Souza-Dias, Celso Marra Pereira, Élcio Roque Kleinpaul, Francisco de Assis Cordeiro Barbosa, Haroldo Vieira de Moraes Júnior, João Brasil Vita Sobrinho, João Luiz Lobo Ferreira, José Paulo Cabral de Vasconcellos, Luiz Alberto S. Melo Júnior, Marcos Pereira de Ávila, Maria de Lourdes Veronese Rodrigues, Procópio Miguel dos Santos, Renato Luiz Nahoum Curi, Rosane da Cruz Ferreira, Rui Barroso Schimiti, Suel Abujamra, Tereza Cristina Nogueira Prazeres.

\section{CONGRESSO DE OFTALMOLOGIA E 6- CONGRESSO DE AUXILIAR DE OfTALMOlocia da USP}

\section{6 c 28 de Novembro de 2004 Cenhre de cenvenğes Reboug̣s Sส̃॰ PaUle - SP}

INFORMAC̣ÕES: Tel.: (11) 5575-0254

Fax: (11) 5539-2186

E-mail: congressousp@terra.com.br Home-page: www.drvisao.com.br 